\title{
Das Band der Gesellschaft
}

\author{
Verbindlichkeitsdiskurse im 18. Jahrhundert \\ Hrsg. v. Simon Bunke, Katerina Mihaylova und Daniela Ringkamp
}

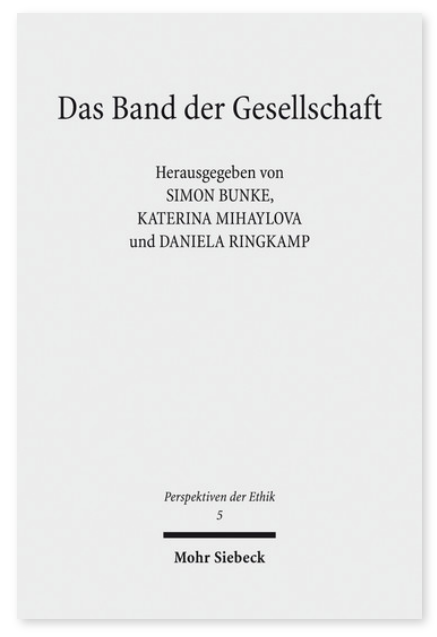

2015. IX, 306 Seiten. PE 5

ISBN 978-3-16-153549-9 DOI 10.1628/978-3-16-153549-9 eBook PDF 74,00€

ISBN 978-3-16-153548-2 fadengeheftete Broschur $74,00 €$
Mit den Rationalisierungsbemühungen der Frühneuzeit ergeben sich weiterreichende Konsequenzen für das Selbstverständnis der Individuen als soziale wie moralische Akteure. Grundlegend ist dabei die Verinnerlichung verbindlichkeitsverbürgender Geltungsmaßstäbe der Moral. Dort, wo rein äußerliche, zivilrechtliche Normen nicht ausreichen, um Stabilität zu garantieren, werden durch Rekurs auf die rationale Einsicht des Vernunftsubjekts anthropologisch legitimierte, natur- und völkerrechtliche Normen eingesetzt, deren Verbindlichkeit internalistischen Legitimationsstrategien unterliegt. Die Beiträge dieses Sammelbandes nehmen aus geistes- und kulturwissenschaftlicher Perspektive die Verschiebungen, Umbrüche und Verwerfungen in den Blick, die der tradierte Begriff der Verbindlichkeit im 18. und frühen 19. Jahrhundert erfahren hat. Dabei liegt nicht nur ein Fokus auf der kantischen Moralphilosophie als dem Höhepunkt einer spezifisch neuzeitlichen Entwicklung, sondern es werden auch alternative Konzepte von Verbindlichkeit in den Blick genommen, die durch Literatur, Ästhetik, Politik und Pädagogik formuliert wurden.

Inhaltsübersicht

\section{Vorwort}

\section{Einleitung}

Theoretische Ansätze und historische Grundlagen von Verbindlichkeit

Oliver Bach: Obligatio. Instanzen und Fundamente von Verbindlichkeit: Melanchthon - Pufendorf - Hobbes - Rousseau Dieter Hüning: Gesetz und Verbindlichkeit. Zur Begründung der praktischen Philosophie bei Samuel Pufendorf und Christian Wolff - Katerina Mihaylova: Vernunft und Verbindlichkeit. Moralische Wahrheit im Natur- und Völkerrecht der deutschen Aufklärung - Georg Eckert: Beliebige Verbindlichkeiten: Zur Formierung eines Konzepts an der Wende zum 19. Jahrhundert Zum Verbindlichkeitsmodell der praktischen Philosophie Immanuel Kants

Stephan Zimmermann: Praktische Kontingenz. Kant über Verbindlichkeit aus reiner praktischer Vernunft - Günter Zöller: »Ohne Hoffnung und Furcht« - Kants Naturrecht Feyerabend über den Grund der Verbindlichkeit zu einer Handlung Bernhard Jakl: Die Verbindlichkeit des Rechts. Kantische Überlegungen zum Verhältnis von privater und staatlicher Normenbegründung - Daniela Ringkamp: Erlaubnis, Erlaubnisgesetz und Verbindlichkeit in Kants Praktischer Philosophie Michae/ Städtler: Warum ist »[d]er Ursprung der obersten Gewalt [...] für das Volk, das unter derselben steht, in praktischer Absicht unerforschlich«? Über systematische Gründe politisch-juridischer Verbindlichkeit bei Kant Rechtlich-politische, pädagogische und ästhetisch-literarische Auseinandersetzungen mit Verbindlichkeit Carolin Pecho: Habsburger-Portraits als Kristallisationspunkte einer verbindlichen Politik Anfang des 17. Jahrhunderts - Till Kinzel: Fiktionale Diskurse der Verbindlichkeit in der britischen Literatur des 18. Jahrhunderts von Daniel Defoe bis William Godwin - Kevin Dear: Verbindlichkeit in der Aufklärungspädagogik. Anmerkungen zu Pestalozzi - Hauke Kuhlmann: Dialog, Verbindlichkeit und Handlungsbrüche in Goethes Iphigenie auf Tauris - Simon Bunke: Verbindlichkeit und Charisma. Überlegungen zu Schillers Wallenstein - Christian Sinn: Vorschule der Ästhetik. Zur Verbindlichkeit unverbindlicher Definitionen bei Jean Paul

Simon Bunke Geboren 1976; Studium der Neueren deutschen Literaturwissenschaft, Komparatistik und Theaterwissenschaft; 2006 Promotion; derzeit Leiter der Emmy Noether Gruppe Aufrichtigkeit in der Goethezeit an der Universität Paderborn.

Katerina Mihaylova Geboren 1982; Studium der Philosophie, Psychologie und Logik und Wissenschaftstheorie; derzeit Doktorandin an der LMU München und wissenschaftliche Mitarbeiterin in der Emmy Noether-Gruppe Aufrichtigkeit in der Goethezeit an der Universität Paderborn.

Daniela Ringkamp Geboren 1981; Studium der Philosophie, Neueren deutschen Literaturwissenschaft und Medienwissenschaft; 2012 Promotion; 2013 Ferdinand Schöningh-Promotionspreis; derzeit Assistentin am Lehrstuhl für praktische Philosophie an der Universität Paderborn.

Jetzt bestellen:

https://mohrsiebeck.com/buch/das-band-der-gesellschaft-9783161535499?no_cache=1

order@mohrsiebeck.com

Telefon: +49 (0)7071-923-17

Telefax: +49 (0)7071-51104 